\title{
Deposition of endothelial fibronectin on polymeric surfaces
}

\author{
P.B. van Wachem, T. Beugeling, B.W.L. Mallens, A. Dekker, J. Feijen, \\ A. Bantjes and W.G. van Aken \\ Department of Chemical Technology, Biomaterials Section. Twente University, P.O. Box 217, 7500 AE Enschede, \\ The Netherlands \\ Presented at Biointeractions '87, Cambridge, UK in July 1987
}

\begin{abstract}
Cellular fibronectin is deposited on tissue culture polystyrene during the adhesion and spreading of cultured human endothelial cells (HEC). Following the seeding of HEC upon this polymer, larger amounts of fibronectin are deposited as both cell density and incubation time increase. Our results indicate that the ability to deposit cellular fibronectin onto a polymeric surface is a condition for the spreading and proliferation of HEC.
\end{abstract}

Keywords: Cells (human endothelial), fibronectin, polymer surface, adhesion, spreading

The clinical results with small diameter vascular grafts made from polymers such as Dacron ${ }^{\circledast}$ (polyethylene terephthalate, PETP) and Teflon are generally disappointing, mainly because of occlusion due to thrombus formation ${ }^{1}$. Since vascular endothelium represents a unique non-thrombogenic surface, endothelial cells are the first logical choice for lining small diameter vascular grafts. A systematic in vitro study of the interaction of human endothelial cells (HEC) with polymers may lead to the development of grafts which promote overgrowth of endothelial cells.

Earlier we reported ${ }^{2}$ that HEC, suspended in a culture medium containing human serum, adhere to moderately wettable polymers such as tissue culture polystyrene (TCPS). Reduced or no adhesion was observed on the more hydrophobic polymer PETP and the very hydrophobic fluoroethylene-propylene copolymer (FEP, a Teflon-like polymer). Recently, we also observed that TCPS adsorbs more of the adhesive protein fibronectin from the culture medium than PETP or FEP, although this amount was small compared to, for example, adsorbed albumin ${ }^{3}$. It seemed unlikely that this relatively small amount of fibronectin was responsible for the adhesion, spreading and proliferation of HEC. Therefore, we studied the deposition of endothelialcell-derived fibronectin to TCPS.

\section{MATERIALS AND METHODS}

\section{Cell culture}

Endothelial cells were isolated from human umbilical cord veins according to the isolation method originally reported by Jaffe et al. ${ }^{4}$ with some modifications ${ }^{5}$.

Cells were routinely cultured in TCPS flasks (Corning, New York, USA) precoated with a partially purified fibronectin (obtained from the Central Laboratory of the Netherlands

Correspondence to Dr P.B. van Wachem.
Red Cross Blood Transfusion Service, Amsterdam, The Netherlands). This fibronectin was obtained during the purification of human coagulation Factor VIII and SDS polyacrylamide gel electrophoresis indicated that a small amount of albumin was present as a contaminant. Fibronectin precoating was performed over a period of $2 \mathrm{~h}$ using a $2 \%$ solution $(\mathrm{W} / \mathrm{v})$ in 'complete medium' (see below).

Serum-containing culture medium (CMS) consisted of complete medium - an equal mixture of medium M 199 and medium RPMI 1640 (both from Gibco Biocult Co., Paisley, UK), with $2 \mathrm{~mm}$ L-glutamine (Merck, Darmstadt, FRG), $100 \mathrm{U} \mathrm{ml}^{-1}$ penicillin, $100 \mu \mathrm{g} \mathrm{ml}^{-1}$ streptomycin (both from Flow Laboratories, Irvine, UK) and $2.5 \mu \mathrm{g} \mathrm{ml}^{-1}$ fungizone (Gibco) - which was supplemented with $20 \%$ human serum (pool from 20 healthy male donors).

Cells were used in experiments after the second or third passage when cultures had reached confluence.

\section{Exposure of TCPS to cell suspensions and culture medium; lysis of adherent cells}

Trypsinization (0.05\% trypsin/0.02\% EDTA) was used to harvest the cells. Trypsin was inactivated with CMS. However, when HEC were to be seeded in the presence of culture medium containing $20 \%$ fibronectin-depleted serum (CMS-Fn) instead of normal serum, trypsin was first inactivated with CMS-Fn. Fibronectin-depleted serum was obtained by Gelatin-Sepharose affinity chromatography of the pooled serum ${ }^{6}$.

TCPS clusters containing 24 wells (obtained from Costar, Cambridge, MA, USA) were used for the study of fibronectin adsorption from culture medium or fibronectin adsorption/deposition from cell suspensions in culture medium. The ratio of the volume of culture medium (with or without cells) to the surface area (bottom of the well) was 0.2 . 
The experiments from which the results are shown in Figure 1 were started at the same time. This was also the case for the experiments presented in Figure 2. Each point on the graph represents an average value for fibronectin adsorption which has been obtained from three experiments carried out in three different wells of a 24-well TCPS cluster. Differences between the adsorption values obtained from three corresponding experiments (values deduced from absorbances of the generated dye in the enzyme immunoassay - see below) ranged from 10-15\%.

At the end of the appropriate exposure time ( $30 \mathrm{~min}$ to $48 \mathrm{~h}$ ), the wells with adherent HEC were rinsed with phosphate buffered saline (PBS, obtained from NPBI, Emmer-Compascuum, The Netherlands) and the cells were lysed.

Cell lysis was performed in the $10 \mathrm{~min}$ after the addition of $0.1 \mathrm{M} \mathrm{NH}_{4} \mathrm{OH}$ (Merck, Darmstadt, FRG) ${ }^{7}$. Thereafter, the deposited protein layer was rinsed three times with PBS, fixed with methanol for $15 \mathrm{~min}$ and rinsed again with PBS. The clusters with test wells, filled with PBS, were stored at $4^{\circ} \mathrm{C}$ before the detection of adsorbed fibronectin. The rinsing and cell lysis procedure was also carried out with wells which were exposed to culture medium without cells.

\section{Detection of adsorbed/deposited fibronectin}

The adsorption/deposition of fibronectin on TCPS was studied by means of a two-step enzyme immunoassay (EIA) which permits the selective detection of adsorbed proteins ${ }^{3,8}$. The adsorbed/deposited fibronectin in the cluster wells were determined as described before ${ }^{3}$. Fibronectin detection was carried out after the rinsing and cell lysis procedure mentioned above.

The first antibody used in the EIA was mouse monoclonal antibody CLB-HEC-Fn 140 which is directed against human fibronectin ${ }^{9}$. This antibody was isolated from ascites by protein $A$ Sepharose chromatography ${ }^{10}$ and stored as a solution of $0.5 \mu \mathrm{g} \mathrm{ml}^{-1}$. Before use in the EIA, it was diluted 100-fold with antibody buffer, which consisted of $8.7 \mathrm{~g} \mathrm{~L}^{-1} \mathrm{NaCl}, 6.1 \mathrm{~g} \mathrm{~L}^{-1}$ Tris (Merck, Darmstadt, FRG), $0.02 \%(v / v)$ Tween-20 (Sigma, St. Louis, MO, USA), $0.21 \%$ $(\mathrm{v} / \mathrm{v})$ gelatin (Merck) and $0.5 \%(\mathrm{w} / \mathrm{v})$ bovine serum albumin (BSA, obtained from Sigma). The $\mathrm{pH}$ was adjusted to 7.5 . The enzyme-labelled second antibody solution contained goat anti-mouse lgG (GMlgG) and horseradish peroxidase labeled $\mathrm{GMIgG}\left(\mathrm{GM} \mathrm{IgG}^{\mathrm{HRP}}\right.$ ). (Both $\mathrm{GMIgG}$ and $\mathrm{GM} / \mathrm{IG}^{\mathrm{HRP}}$ were obtained from the Central Laboratory of the Netherlands Red Cross Blood Transfusion Service.) GMigG ${ }^{\text {HRP }}$ was diluted 20-fold with GMIgG and then 10000 -fold with conjugate buffer. The conjugate buffer had the same composition as the first antibody buffer except for the concentration of BSA which was $5 \%$.

The relative fibronectin-adsorption data, presented in the figures are deduced from absorbances of the generated dye in the EIA. These data are not directly related to amounts of adsorbed fibronectin $/ \mathrm{cm}^{2}$.

\section{RESULTS}

The adsorption of fibronectin to TCPS from serum-containing culture medium and its adsorption/deposition from the culture medium in which $4 \times 10^{4} \mathrm{HEC} / \mathrm{cm}^{-2}$ TCPS were suspended, are shown in Figure 1.

The adsorption of fibronectin to TCPS from culture medium without cells reached a plateau value after about $2 \mathrm{~h}$. The fibronectin deposition on TCPS from the culture medium in which $\mathrm{HEC}$ were suspended, showed an increase

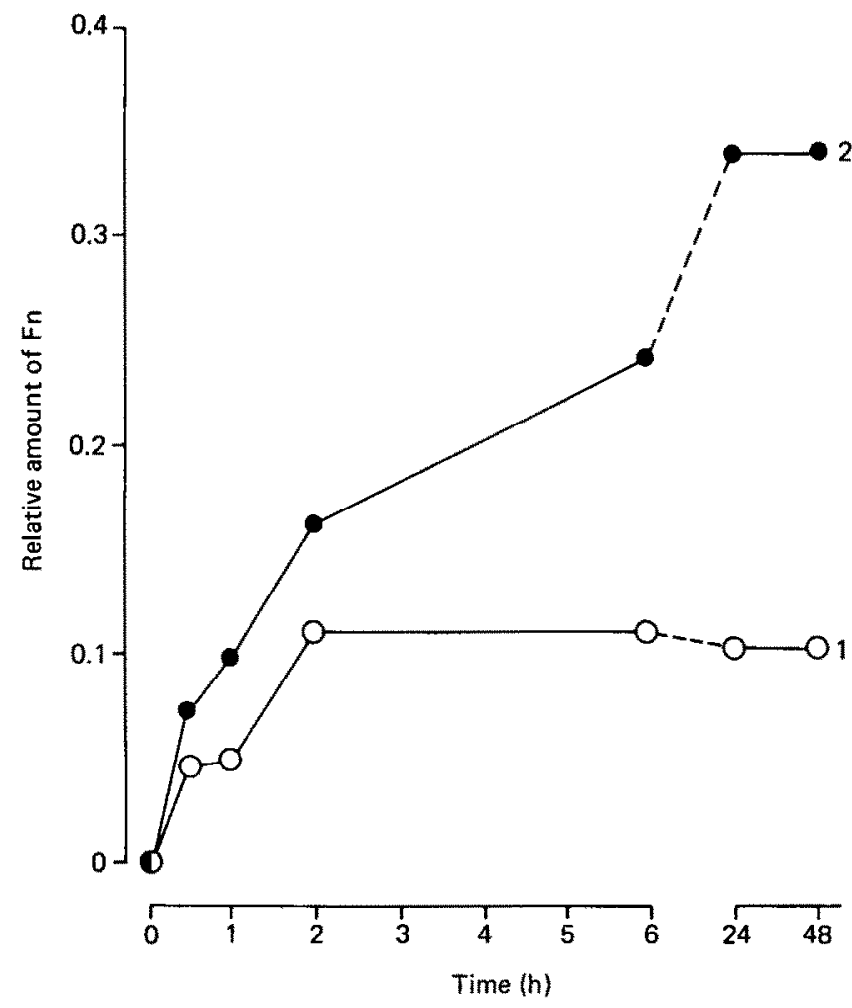

Figure 1 Adsorption/deposition of fibronectin an TCPS from serumcontaining culture medium (1), and from serum-containing culture medium in which $4 \times 10^{4} \mathrm{HEC} \mathrm{cm}^{-2}$ TCPS were suspended (2). The experiments were started at the same time. Each point represents an average value which has been obtained from three experiments carried out in three different wells of a TCPS cluster. Differences between the values obtained from three corresponding experiments ranged from $10-15 \%$.

with the time of exposure of the TCPS surface to the cell suspension.

The fibronectin deposition on TCPS from HEC suspended in a culture medium which contained fibronectin-depleted serum is shown in Figure 2. The deposition of endothelial fibronectin increased both with increasing cell density and

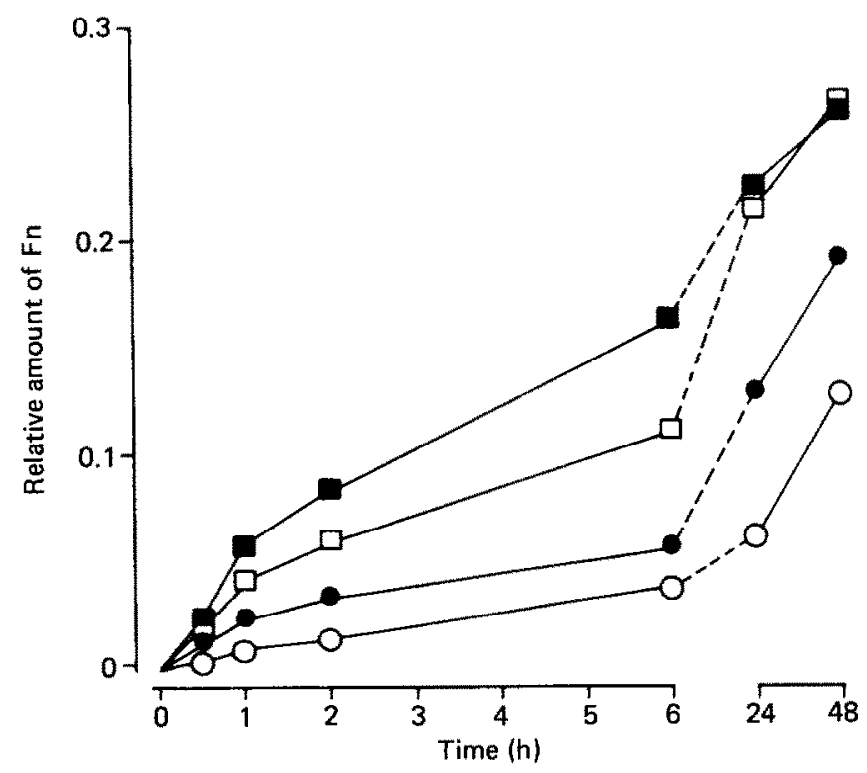

Figure 2 Deposition of endothelial fibronectin on TCPS. $0,1.0 \times 10^{4}$ cells $\mathrm{cm}^{-2} ; 2.0 \times 10^{4} \mathrm{cells}^{-2} \mathrm{~cm}^{-2} ; 0,3.0 \times 10^{4} \mathrm{cells}^{-2} ; \mathrm{cm}, 4.0 \times 10^{4}$ cells $\mathrm{cm}^{-2}$. HEC were suspended in culture medium containing fibronectin. depleted serum. Different cell densities were used for seeding. The experiments were started at the same time. Each point represents an average value which has been obtained from three experiments carried out in three different wells of a TCPS cluster. Differences between the values obtained from three corresponding experiments ranged from $10-15 \%$ 
with the time of exposure of the TCPS surface to the seeded cells.

No fibronectin could be detected on the TCPS surface if the surface was exposed to culture medium containing fibronectin-depleted serum without cells (not shown).

Optical phase-contrast microscopy revealed that the adhesion and spreading rate of HEC were similar during the 6 h after seeding $4 \times 10^{4}$ cells $\mathrm{cm}^{-2}$, whether the cells were suspended in culture medium containing normal serum or in culture medium containing fibronectin-depleted serum. Spreading of HEC on TCPS started about $30 \mathrm{~min}$ after cell seeding. After about $16 \mathrm{~h}$ cell proliferation started.

\section{DISCUSSION}

Fibronectin is present in the extracellular matrix and in the subendothelium as a fibrillar network which mediates platelet adhesion. It is synthesized and secreted in culture medium by human endothelial cells ${ }^{9,11}$. Recently. Clark et $a .^{12}$ found that human endothelial cells grown in vitro from umbilical veins produced fibronectin to adhere to collagen which had been preadsorbed to (unmodified) polystyrenc.

Our results show that cellular fibronectin is deposited on TCPS when human endothelial cells cultured from umbilical veins are seeded upon this polymer surface and that this occurs whether the culture medium in which the cells are suspended contains normal serum or fibronectindepleted serum. From the results presented in Figure 2 we conclude that the amount of deposited fibronectin increases both with cell density and the time of exposure of a TCPS surface to the seeded cells. From Figures 1 and 2 it can be concluded that cellular fibronectin was already present at the TCPS surface $30 \mathrm{~min}$ after HEC were seeded in the wells of the clusters. This suggests that HEC start fibronectindeposition immediately after sedimenting on the TCPS surface.

Reinders et $a / .^{9}$ found that cultured human vascular endothelial cells probably do not contain a storage site for fibronectin. They concluded that the rate of secretion is determined solely by the rate of newly synthesized fibronectin. Therefore it is likely that no fibronectin originating from the cytoplasma had been released and subsequently deposited on the TCPS surface during cell lysis prior to the enzyme immunoassay (EIA).

The applied EIA does not yet allow a quantitative detection of adsorbed proteins. Preliminary experiments carried out by Breemhaar ${ }^{13}$ indicate that an absorbance of 1.0 of the dye solution generated in the EIA corresponds to about $70 \mathrm{ng}$ adsorbed albumin $\mathrm{cm}^{-2}$. If it is assumed that an absorbance of 0.1 in our experiments corresponds to $7 \mathrm{ng}$ deposited fibronectin $\mathrm{cm}^{-2}, 4 \times 10^{4}$ seeded HEC deposit about $7 \mathrm{ng}$ fibronectin upon $1 \mathrm{~cm}^{-2}$ of TCPS over $6 \mathrm{~h}$. For $8 \times 10^{4}$ cells this value is $11 \mathrm{ng}$. In other words, one endothelial cell should deposit about $15 \mathrm{pg}$ fibronectin over $6 \mathrm{~h}$.

Earlier we reported that TCPS, which is moderately wettable, adsorbs more fibronectin from (undiluted) serumcontaining culture medium than hydrophobic polymers such as PETP and FEP although this amount is small compared to, for example, adsorbed albumin ${ }^{3}$. Much more fibronectin adsorbs to TCPS from diluted culture medium; this is not found in case of PETP and FEP. From these data it may be concluded that TCPS shows a relatively high affinity for fibronectin.

The present results prove that the small amount of fibronectin adsorbed to TCPS from undiluted culture medium is not responsible for the spreading and proliferation of seeded HEC, because HEC also spread and proliferated on this polymer when the culture medium was fibronectindepleted. Evidently, the high affinity of TCPS for fibronectin and the nature of the adsorbed serum protein layer permit the cells to deposit their own fibronectin onto the polymer surface. A possible mechanism is that TCPS shows an exchange of surface bound serum proteins for cell secreted fibronectin. Such a process is expected to proceed at a much slower rate in case of more hydrophobic polymers ${ }^{14}$ like PETP and FEP, which show strongly reduced $H E C$ adhesion ${ }^{2}$.

Spreading of HEC on TCPS starts about $30 \mathrm{~min}$ after cell seeding. In time more cells spread on the TCPS surface and after about $16 \mathrm{~h}$ cell proliferation starts. During these processes more fibronectin is deposited on the TCPS surface. Our results indicate that the ability to deposit cellular fibronectin onto a polymeric surface is a condition for the spreading and proliferation of HEC.

\section{ACKNOWLEDGEMENT}

We thank Louise Rotman for her aid in the preparation of this manuscript.

\section{REFERENCES}

1 Stanley, J.C., Burkel, W.E., Lindenaver, S.M., Bartlett, R.H. and Turcotte, J.G., Biologic and Synthetic Vascular Prostheses, Grune \& Stratton, New York, 1982

2 Wachem, van, P.B., Beugeling, T., Feijen, J., Bantjes, A., Detmers, J.P. and Van Aken. W.G. Interaction of cultured human endothelial cells with polymeric surfaces of different wettabilities, Biomaterials 1985 . 6, 403-408

3 Wachem, van, P.B., Vreriks, C.M., Beugeling. T., Feijen, J., Bantjes, A Detmers, J.P. and Van Aken, W.G. The influence of protein adsorption on interactions of cultured human endothelial cells with polymers, $J$ Biomed. Mat. Res. 1987, 21, 701-718

4 Jaffe, E.A., Nachman, R.L., Becker, C.G. and Minick, C.R., Culture of human endothelial cells derived from umbilical veins. Identification by morphologic and immunologic criteria, J. Clin. Invest. 1973, 52, 2745

5 Willems, Ch., Astaldi, G.C.B., De Gront, Ph.G., Janssen, M.C. Gonsalves, M.D., Zeiilemaker, W.P., van Mourik, J.A. and Van Aken, W.G. Media conditioned by cultured vascular smooth muscle cells Exp. Cell. Res. 1982, 139, 191

6 Ruoslahti, E., Hayman, E.G., Piersbacher, M. and Engyall, E., Fibronectin purification, immunochemical properties and biological activity, Methods in Enzymology 1982, 82, 803-831

7 Sakariassen, K.S., Aarts, P.A.M.M., De Groot, Ph.G., Houdijk, W.P.M and Sixma, J.J., A perfusion chamber developed to investigate platelet interaction in flowing blood with human vessel wall cells, their extracellular matrix and purified components, J. Lab. Clin. Med. 1983, 102, 522-535

8 Breemhaar, W., Brinkman, E., Ellens, D.J., Beugeling, T. and Bantjes, A., The interaction of polymers and blood plasma: preferential adsorption of high density lipoprotein from blood plasma onto biomaterial surfaces, Biomaterials $1984,5,269-274$

9 Reinders, J.H., De Groot, P. G., Dawes, J., Hunter, N.R., van Heugten, H.A.A., Zandbergen, J., Gonsalves, M.D. and Van Mourik, J.A., Comparison of secretion and subcellular localization of von Willebrand protein with that of thrombospondin and fibronectin in cultured human vascular endothelial cells, Biochem. Biophys. Acta 1985, 844, 306-313

10 Goding, J.W., Conjugation of antibodies with fluorchromes: modification to the standard methods, J. Immunol. Methods $1976,12,215$

11 Jaffe, E.A. and Mosher, D.F., Synthesis of fibronectin by cultured human endothelial cells, J. Exp. Med. 1978, 147. 1779-1791

12 Clark, R.A.F., Folkvord, J.M. and Nielsen, L.D. Either exogenous or endogenous fibronectin can promote adherence of human endothelial cells, J. Cell. Sci. 1986, 82, 263-280

13 Breemhaar, W. An Enzyme Immunoassay for the Detection of Blood Components Adsorbed to Polymeric Surfaces. Thesis. Twente University of Technology, Enschede, The Netherlands, October 1985

14 Feijen, J., Beugeling, T., Bantjes, A. and Smit Sibinga, C.Th., Biomaterials and interfacial phenumena, in: D.N. Ghista (ed.). Advances in Cardiovascular Physics 1979, Volume 3, 100-132, Karger, Basel, 1979 